\section{Exacerbations in non-COPD patients: recognition?}

\author{
Gavin C Donaldson
}

COPD is a progressive lung disease that leads to significant impairment of quality of life and is the third leading cause of death worldwide. ${ }^{1}$ It is principally caused by tobacco smoking over many years through airway inflammation and oxidative stress to lung tissue. Patients exposed to smoke or occupational dusts are diagnosed with the disease when their postbronchodilator $\mathrm{FEV}_{1} / \mathrm{FVC}$ ratio falls to $<0.7 .^{2}$ Disease severity is assessed differently by expressing the measured $\mathrm{FEV}_{1}$ as a percentage of the expected value for normal, healthy people of similar sex, age and height. The threshold value of $<0.7$ for the $\mathrm{FEV}_{1} / \mathrm{FVC}$ ratio is arbitrary and may not always identify people in the early stages of COPD with smoking-related lung damage.

COPD exacerbations (the flare-up of respiratory symptoms) are often triggered by viral or bacterial infection and cause patients sometimes to seek medical help. Attention has focused on those patients most susceptible to exacerbation as the disease appears to progress more rapidly in this group, and consequently, they form a high proportion of the group with most severe disease irrespective of the outcome measure. ${ }^{3}$ However, studies show that exacerbations occur even in patients with the least severe COPD. ${ }^{5}$

The study by Tan and colleagues ${ }^{6}$ examined respiratory symptoms in those with and without COPD. They found half the rate of 'exacerbation-like' events in non-COPD patients compared with patients with COPD. In the former, health-related quality of life was poorer with social and physical activity reduced compared with those with no events. The exacerbation-like events in non-COPD patients were more frequent in women, those who were wheezing or using respiratory drugs and in poor health, though no association was seen with chronic cough or chronic sputum production. A key strength of the study was that subjects were selected by established criteria to achieve a representative sample of the general population, and the overall participation rate of $74 \%$

Correspondence to $\operatorname{Dr}$ G C Donaldson, Airway Disease Section, National Heart and Lung Institute, Emmanuel Kaye Building, Manresa Road, London SW3 6LR, UK; gavin.donaldson@imperial.ac.uk was good. There were two important limitations-namely, patients with undetected asthma, COPD, or emphysema could not be excluded and there is a risk of bias in that individuals with respiratory symptoms might be more eager to participate in such a study.

There is no logical reason why an acute episode of respiratory symptoms cannot occur in people without COPD. Indeed, very few of us have not taken time off work, put off social engagements and stayed indoors because of a respiratory infection-for example, a common cold. We experienced symptoms of nasal congestion, coughing and, occasionally, brought up sputum. These episodes may not be called exacerbations but are similar in most respects, apart possibly from breathlessness, as sufficient reserves remain in the respiratory system. These events do not receive much medical attention as few normally healthy people would or should seek professional healthcare. They are not, however, ignored by the pharmaceutical industry, which profits by selling over-the-counter anti-tussive drugs, expectorants, mucolytic agents and anti-histamine decongestants to people who self-medicate. One reason why we might not seek medical attention for these episodes is that we have experienced them since birth and always recovered. This acceptance of respiratory infection might explain why people are admitted to hospital with an acute COPD exacerbation but have not previously been diagnosed with the disease. $^{7}$

The finding that episodes of respiratory symptoms can occur in non-COPD (healthy) individuals does not imply that they will have COPD. There is a danger that elderly but normal people will in the aftermath, especially if their $\mathrm{FEV}_{1} / \mathrm{FVC}$ ratio has dipped below the threshold, be prescribed respiratory drugs-possibly for the rest of their lives if follow-up is poor. As long as respiratory viruses and pathogenic bacteria circulate in the community these respiratory episodes are normal events. However, sometimes exacerbations cause lasting damage to the respiratory system. In patients with COPD, only in about $7.1 \%$ of exacerbations did the peak expiratory flow clearly not recover to pre-exacerbation levels. ${ }^{8}$ In childhood, respiratory infections impair lung development. ${ }^{9}$ More long-term research is needed to identify the cause of these events as these infections might also occur in the healthy adult population.

Opportunities for early diagnosis of COPD should not be missed. ${ }^{10}$ It has been known for some time, for example, that chronic mucus hypersecretion is associated with excess $\mathrm{FEV}_{1}$ decline in the general population. ${ }^{11}$ There are no treatments that can reliably reduce disease progression apart from smoking cessation and perhaps, increasing physical activity, ${ }^{12}$ but these need to be started early. Patients who meet the spirometric criteria for COPD may already have had a considerable and irreversible loss of small airways and lung function. A warning about respiratory symptoms in middle-age, possibly bronchitis or breathlessness on mild exertion, may be the public health warning catchphrase that is needed to alert those at risk. Such a warning might prompt the millions with undetected disease ${ }^{13}$ to seek treatment. However, the evidence about which symptoms and signs best identify the onset of COPD is lacking and consequently, longitudinal follow-up of cohorts with respiratory symptoms with normal or mild airflow limitation is required.

Competing interests None.

Provenance and peer review Commissioned; internally peer reviewed.

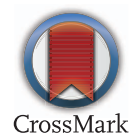

To cite Donaldson GC. Thorax 2014;69:689-690.

Published Online First 2 May 2014

Thorax 2014;69:689-690.

doi:10.1136/thoraxjnl-2014-205355

\section{REFERENCES}

1 Lozano R, Naghavi M, Foreman K, et al. Global and regional mortality from 235 causes of death for 20 age groups in 1990 and 2010: a systematic analysis for the Global Burden of Disease Study 2010. Lancet 2012;380:2095-128.

2 Vestbo J, Hurd SS, Agustí AG, et al. Global strategy for the diagnosis, management, and prevention of chronic obstructive pulmonary disease. Am J Respir Crit Care Med 2013;187:347-65.

3 Hurst JR, Vestbo J, Anzueto A, et al. Susceptibility to exacerbation in chronic obstructive pulmonary disease. N Engl J Med 2010;363:1128-38.

4 Donaldson GC, Mullerova H, Locantore N, et al. Factors associated with change in exacerbation frequency in COPD. Respir Res 2013;14:79.

5 Burge S, Wedzicha JA. COPD exacerbations: definitions and classifications. Eur Respir I Supp/ 2003:41:46s-53s.

6 Tan WC, Bourbeau J, Hernandez P, et al. Exacerbation-like respiratory symptoms in individuals without chronic obstructive pulmonary disease: results from a population-based study. Thorax 2014;69:709-17. 
7 Bastin A, Starling L, Ahmed R, et al. High prevalence of undiagnosed and severe chronic obstructive pulmonary disease at first hospital admission with acute exacerbation. Chronic Respir Dis 2010;7:91-7.

8 Seemungal TA, Donaldson GC, Bhowmik A, et al. Time course and recovery of exacerbations in patients with chronic obstructive pulmonary disease. $\mathrm{Am} J$ Respir Crit Care Med 2000;161:1608-13.

9 Barker DJ, Godfrey KM, Fall C, et al. Relation of birth weight and childhood respiratory infection to adult lung function and death from chronic obstructive airways disease. BMJ 1991:303: 671-5.

10 Jones RCM, Price D, Ryan D, et al. Opportunities to diagnose chronic obstructive pulmonary disease in routine care in the UK: a retrospective study of a clinical cohort. Lancet Respir Med 2014;2:267-76.

11 Vestbo J, Prescott E, Lange P. Association of chronic mucus hypersecretion with FEV1 decline and chronic obstructive pulmonary disease morbidity.

Copenhagen City Heart Study Group. Am J Respir Crit Care Med 1996;153:1530-5.
12 Price D, Freeman D, Cleland J, et al. Earlier diagnosis and earlier treatment of COPD in primary care. Primary Care Respir J 2011; 20:15-22.

13 Department of Health. An outcomes strategy for people with chronic obstructive pulmonary disease (COPD) and asthma in England. https://www.gov.uk/ government/uploads/system/uploads/attachment data/file/216139/dh_128428.pdf 